\title{
Simple and Micro Determination of Manganese in Serum by Graphite Furnace Atomic Absorption Spectrometry
}

\author{
Tetsuo Uchida and Bert L. ValleE \\ Center for Biochemical and Biophysical Sciences and Medicine, Harvard Medical School, 250 \\ Longwood Avenue, Boston, Mass. 02115 USA \\ T. U.: On leave from Laboratory of Analytical Chemistry, Nagoya Institute of Technology, \\ Gokiso, Showa, Nagoya 466
}

\begin{abstract}
A method for the determination of low level manganese in serum by graphite furnace atomic absorption spectrometry was established. Serum was diluted two-fold with Triton X-100 without deproteinization. The final concentration of the detergent was $0.2 \%$. Manganese was measured twice by $20 \mu$ injection of sample solution by a standard addition method. For the serum manganese of $0.52 \mathrm{ng} / \mathrm{ml}$, the relative standard deviation was below $5 \%$. Special precautions for sampling of serum and some sources of contamination are also described.
\end{abstract}

Keywords Manganese in serum, graphite furnace atomic absorption spectrometry, Triton X-100, standard addition method, contamination control

It has been widely accepted that the manganese in normal serum was $0.5-0.6 \mathrm{ng} / \mathrm{ml}$, even though slightly or enormously higher values have been reported in that last decade. ${ }^{1}$ These low concentrations were obtained by neutron activation analysis $^{2-4}$ or by catalytic reaction. ${ }^{5}$ Compared to these elaborate but tedious methods, atomic absorption spectrometry with a graphite furnace would be extremely simple, fast, and sensitive enough for the measurement of serum manganese. Further, its widespread use in various field, especially in clinic, should facilitate the measurement of this element in serum. However, the lowest value reported using this easy method was around $1 \mathrm{ng} / \mathrm{ml}$, i.e., almost twice of the normal, and the relative standard deviation was as high as $12 \% .^{6}$ The major reasons for this high value and poor reproducibility would be the lack of stringent precautions in the sampling, storage and measurement. For the determination of ultratrace mangamese in serum, it should be essential to minimize the contaminations from other sources: such as reagents, sampling method and devices, laboratory wares and laboratory environment..$^{3,7-9}$

In the present paper, the simple and micro procedure for the determination of manganese in serum is described using $200 \mu \mathrm{l}$ of sample. Special techniques to avoid contamination in an ordinary laboratory as well as possible contamination sources in an old method are also described.

\section{Experimental}

\section{Apparatus and equipment}

The Perkin-Elmer HGA 500 Graphite Furnace with pyrolytically coated graphite tubes was used in combination with Model 5000 Atomic Absorption Spectrophotometer, AS-40 Auto Sampler, PRS-10 Printer Sequencer and Model 056 Recorder. An adjustable digital micropipette (Gilson, Pipetman P2000) with polypropylene tips (C-20) were used for preparation of solutions. For containers of blood and serum, polypropylene microsample tubes (Bel-Art Products, \#F19929, $1.5 \mathrm{ml}$ ) and polypropylene microcentrifuge tubes (VWR Scientific, \#20170-310, $0.5 \mathrm{ml}$ ) were used. Reagnets were stored in linear polyethylene wide mouth bottles (Nalgene, \#2104-0001) or Teflon narrow mouth bottles (Nalgene, \#1600-0004). Polystyrene sampling cups (Fisher, \#2-544, $2 \mathrm{ml}$ ) for auto sampler were used with polyethylene caps (Fisher, \#2544-10). Vortex Mixer for mixing of solutions, Microcentrifuge (Eppendorf, Model 5412) for serum separation, and Lyophilizer (Virtis, Model 10-100W) for drying of cleaned laboratory wares were also used.

\section{Cleaning of laboratory ware}

Polypropylene tubes and Teflon bottles were immersed in $4 \mathrm{M}$ hydrochloric acid for 1 week in a Pyrex beaker covered with a watch glass, and the beaker was heated to just before boiling for 1 day on a hotplate. 
The tubes were rinsed with water and immersed again in diluted hydrochloric acid $(-\mathrm{pH} 1)$ for 1 day and heated as previously described. After the final rinsing with water, the tubes were dried under reduced pressure on the lyophilizer, and stored in polyethylene bags (Bel-Art Products, \#F13176-0610) until use. In a similar way, polyethylene bottles were cleaned with gentle heating, and polystyrene cups and caps were cleaned without heating. The cups with caps were wrapped with clear polyethylene film (Union Carbide Corp., GLAD WRAP) after drying. Pipette tips were dipped in $6 \mathrm{M}$ nitric acid for 1 day and rinsed with water just before use.

\section{Reagents and standards}

Triton X-100 (Octylphenoxypolyethoxyethanol, Sigma, \#T-6878) was diluted stepwise to the final concentration of $0.5 \mathrm{w} / \mathrm{w} \%$ in $25 \mathrm{mM}$ hydrochloric acid. The working standard $(10 \mathrm{ngMn} / \mathrm{ml}, 10 \mathrm{mM}$ $\mathrm{HCl}$ ) was prepared daily by stepwise 10 -fold dilutions of an intermediate standard with $10 \mathrm{mM}$ hydrochloric acid. The intermediate one $(10 \mu \mathrm{gMn} / \mathrm{g}, 10 \mathrm{mM} \mathrm{HCl})$ was prepared from the Atomic Absorption Reference Standard Solution (Fisher, $1 \mathrm{mgMn} / \mathrm{ml}$, \#So-M-81) by one-step dilution in the polyethylene bottle by mass to minimize the contamination from volumetric glassware. Ultrapure hydrochloric acid (Alfa, \#87617) was used without further purification. Tap water was purified by successive passing through a filter (Commercial Filter Co., BRX 8), colloid removal cartridge (Barnstead, D 0755), demineralizer cartridge (Barnstead, D 0803) and by final distillation with Pyrex Still (Barnstead, $41 / \mathrm{h}$, A 1050). Pooled plasma was obtained from the clinical laboratory of our Hospital.

\section{Procedure}

Blood sampling and serum separation. Sample blood was taken by venipuncture of antecubital fossa with a catheter needle (Desert, Angiocath, 18GA, \#2955). After pulling out of the center needle, auto-bleeding blood through the outer Teflon catheter kept in the vein was collected directly into a large polypropylene tube, allowed to clot for $\mathbf{4 0 ~} \mathrm{min}$, and centrifuged for $\mathbf{1 5}$ min. The serum was transferred to small tube with a micropipette and stored at $4^{\circ} \mathrm{C}$ in a sealable plastic box containing water in its bottom to prevent evaporation and contamination.

Measurement of serum manganese. Manganese was determined by the standard addition method as follows. Into the polystyrene sample cups for auto sampler containing $80 \mu \mathrm{l}$ of $0.5 \%$ Triton $\mathrm{X}-100$ and 20 $\mu \mathrm{l}$ of $10 \mathrm{ngMn} / \mathrm{ml}$ standard solution or water, $100 \mu \mathrm{l}$ each of serum was added with a micropipette. For mixing and reproducible transfer of serum, pipette tips were filled in and out of the sample solution 10-times. The blank solution was similarly prepared with water instead of serum. Using these three solution as one set, manganese was measured with two $20 \mu \mathrm{l}$ portions of each solution by the graphite furnace atomic absorp-
Table 1 Optimum operating conditions

$\begin{array}{ll}\text { (a) Spectrophotometer setting } & \\ \text { Wavelength } & 279.5 \mathrm{~nm} \\ \text { Slit band width } & \mathrm{L}-0.2 \mathrm{~nm} \\ \text { Lamp* current } & 10 \mathrm{~mA} \text { (*Intensitron) } \\ \text { Scale expansion } & \times 10 \\ \text { Time constant } & 0.3 \mathrm{~s} \\ \text { Measurement mode } & \text { AA-BG, Peak height }\end{array}$

\begin{tabular}{ccrccl}
\hline (b) Temperature program of graphite furnace & \\
Setp & $\begin{array}{c}\text { Temp./ } \\
\text { ㅇ }\end{array}$ & $\begin{array}{c}\text { Ramp/ } \\
\text { s }\end{array}$ & $\begin{array}{c}\text { Hold } / \\
\text { s } /\end{array}$ & $\begin{array}{c}\text { ml min } \\
\text { m }\end{array}$ & Remarks \\
\hline 1 & 110 & 5 & 45 & 300 & Drying I \\
2 & 200 & 20 & 0 & 300 & Drying II \\
3 & 600 & 20 & 10 & 300 & Charring I \\
4 & 1300 & 35 & 30 & 300 & Charring II \\
5 & 2600 & 2 & 5 & 30 & Atomizing \\
6 & 2700 & 1 & 5 & 300 & Clean-up \\
\hline
\end{tabular}

tion spectrometry under the optimum operating conditions listed in Table 1.

\section{Results and Discussion}

\section{Operating parameters of graphite furnace}

The settings of temperatures and argon flow rates in drying, charring and atomizing steps of the graphite furnace were very important for the reproducible and reliable signal in high sensitivity. The optimum operating conditions were selected as follows, using pooled plasma and fresh serum. Each sample was diluted 2-fold and spiked with $1 \mathrm{ngMn} / \mathrm{ml}$ in the presence of $0.2 \%$ Triton $\mathrm{X}-100$ and $10 \mathrm{mM}$ hydrochloric acid.

In the first drying step, $20 \mu \mathrm{l}$ of sample was dried without spattering at $110^{\circ} \mathrm{C}$ for $45 \mathrm{~s}$ and completely dried in the second heating to $200^{\circ} \mathrm{C}$. Charring was of extreme importance in the present procedure and twostep charring was undertaken. Organic substances in the sample were burnt out to ashes in the first step at $600^{\circ} \mathrm{C}$ for $10 \mathrm{~s}$, and the residue was vaporized by gradual heating to $1300^{\circ} \mathrm{C}$, followed by 30 s holding to reduce the background absorption caused by the substances which remained in the tube. The effects of time and temperature of ramp and hold in the second charring are mentioned later in detail. Finally, in the atomizing step at $2600^{\circ} \mathrm{C}$, the manganese signal was measured by peak height mode with background correction. With decreasing rate of argon flow in the atomizing, the signal was increased. Though the highest signal was obtained by the interruption of argon, it would cause a short life-span of each graphite tube and poor reproducibility. High and reproducible signals were obtained at the low flow rate of 30 $\mathrm{ml} / \mathrm{min}$. With the shorter ramp time in the atomizing, 


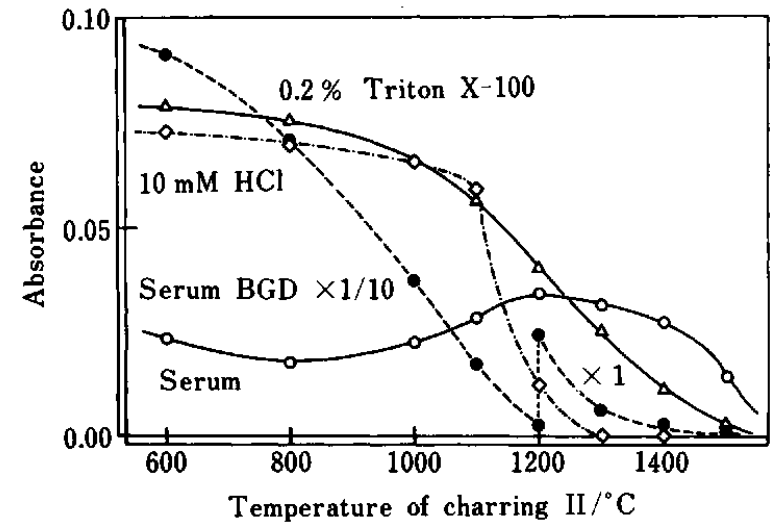

Fig. 1 Effect of charring temperature on manganese signal and background. $\diamond: 2 \mathrm{ngMn} / \mathrm{ml}, 10 \mathrm{mM} \mathrm{HCl} ; \triangle: 2$ $\mathrm{ngMn} / \mathrm{ml}, 10 \mathrm{mM} \mathrm{HCl}$ and $0.2 \%$ Triton X-100; $\mathrm{O}$ : serum $(\times 2$ dilution $+1 \mathrm{ngMn} / \mathrm{ml}, 10 \mathrm{mM} \mathrm{HCl}$ and $0.2 \%$ Triton $\mathrm{X}-100)$; : background of serum (same as above).

the higher signal was also observed. However, the maximum heating (ramp time $=0$ ) was not used, as the background correction might be insufficient.

The effect of the temperature in the second charring step to the manganese signal in some matrices is shown in Fig. 1. The ramp rate of temperature and hold time were kept constant at $20^{\circ} \mathrm{C} / \mathrm{s}$ and $30 \mathrm{~s}$, respectively. Consequently, the ramp time was defined by the hold temperature. Other parameters were fixed as shown in the optimum operating conditions. The signal produced by the standard $(2 \mathrm{ngMn} / \mathrm{ml}, 10 \mathrm{mM} \mathrm{HCl})$ was kept constant up to $1100^{\circ} \mathrm{C}$ and decreased suddenly above $1200^{\circ} \mathrm{C}$. By the addition of $0.2 \%$ Triton X-100, the signal decreased gradually with the increasing temperature above $1000^{\circ} \mathrm{C}$. On the other hand, the signal of serum spiked with $1 \mathrm{ngMn} / \mathrm{ml}$ was still high enough even at $1400^{\circ} \mathrm{C}$.

Background absorption of serum decreased rapidly with the increase in charring temperature and became the same level as the manganese signal observed for unspiked serum at $1300^{\circ} \mathrm{C}$. It was impossible to diminish the background at higher charring temperature than $1300^{\circ} \mathrm{C}$ without significant loss of manganese. Obviously, background absorption was one of the noises interferring with the main signal. The lower background was favorable for secure compensation by the automatic background correction system with deuterium lamp. Under the extraordinary high background as observed at the charring temperature below $1100^{\circ} \mathrm{C}$, the correction system worked insufficiently and the manganese signals were lower than that observed at $1200^{\circ} \mathrm{C}$, as shown in Fig. 1 .

Although some losses of manganese, even in small amounts, would be expected in the final charring at $1300^{\circ} \mathrm{C}$ for $30 \mathrm{~s}$, this effect could be corrected by the standard addition method assuming no difference in atomizing behavior between the manganese originally present in serum and that added as a spike. This assumption might be reasonably valid during the second charring and atomizing steps, for the manganese added was mixed with serum before injection and could be uniformly distributed in the sample, and then it was dried and charred in the presence of large amounts of sample constituents as well as Triton X100. The in-tube addition of standard to the sample prior to the drying step showed a poor reproducibility even if it was added with auto sampler.

Slow ramp rate $\left(<10^{\circ} \mathrm{C} / \mathrm{s}\right)$ or long hold time $(>30 \mathrm{~s})$ in the second charring was not so effective for reducing background; it also required an impractically long time in measurement cycles. Though high ramp rate and short hold time enabled quick measurements, these were also accompanied by high background.

Every attempt for matrix matching or matrix modification failed; these included the addition of major serum electrolytes to standards for calibration, ammonium dihydrogenphosphate addition to both sample and standard, the use of artificial plasma as standard matrix, and partial removal of proteins by precipitation with hydrochloric or nitric acids. The use of normal control serum as standard also failed, owing to the abnormally high content of manganese in it. As evident from Fig. 1, the background correction and the standard addition method were essential.

\section{Effects of Triton $X-100$ and hydrochloric acid}

The effect of Triton X-100 was examined in the range from 0.01 to $0.8 \%$. Below $0.05 \%$ the carbon residue remained even after the clean-up step, and it accumulated in the graphite tube for every measurement. Above $0.05 \%$ no changes were observed up to $0.8 \%$ in either the manganese signal or background, while higher content of Triton X-100 was rather troublesome in pipetting due to its viscosity. The critical miceller concentration of this detergent was $c a$. $0.2 \%$ from the measurement of electro-conductivity with $1000 \mathrm{~Hz}$ A.C. For dilution of serum, $0.2 \%$ Triton $\mathrm{X}-100$ was used; this facilitated the uniform spreading of sample solution on the graphite surface with the lowering of the viscosity of the solution, and resulted in good reproducibility and in the absence of any memory effect in the measurements.

The effect of hydrochloric acid was also checked; no influence was observed to either signal or background in the range from 5 to $100 \mathrm{mM}$. On the other hand, the presence of nitric acid caused carbon debris remaining in the graphite tube even in the low concentration of 5 $\mathrm{mM}$, irrespective of its source (the added standard prepared from the stock containing nitric acid or its addition to the sample).

\section{Contamination}

The water used contained less than $0.01 \mathrm{ngMn} / \mathrm{ml}$. This value was determined after the lyophilization of 50 $\mathrm{ml}$ water in the cleaned Teflon bottle, followed by washing the inner wall with $0.1 \mathrm{M}$ nitric acid of $1 \mathrm{ml}$. 
Table 2 Contamination from sampling devices

\begin{tabular}{llcc}
\hline Container & Solvent & \multicolumn{2}{c}{ Storage/ } \\
& & hn found/ & ng ml-1 \\
\hline Vacutainer, Heparin & water & 24 & 2.33 \\
ditto & $10 \mathrm{mM} \mathrm{HCl}$ & 24 & 2.59 \\
ditto & plasma & 24 & 4.27 \\
Vacutainer, No additive & water & 24 & 0.06 \\
ditto & $10 \mathrm{mM} \mathrm{HCl}$ & 24 & 0.68 \\
ditto & plasma & 24 & 1.59 \\
ditto, with Parafilm seal $10 \mathrm{~m} \mathrm{M} \mathrm{HCl}$ & 24 & 0.40 \\
Syringe (5 ml) with & $10 \mathrm{mM} \mathrm{HCl}$ & 24 & 0.18 \\
needle & & & \\
ditto, without needle & $10 \mathrm{mM} \mathrm{HCl}$ & 24 & $<0.02$ \\
Syringe (10 ml) with & $10 \mathrm{mM} \mathrm{HCl}$ & 24 & 0.09 \\
needle & & & \\
ditto, without needle & $10 \mathrm{~m} \mathrm{M} \mathrm{HCl}$ & 24 & 0.03 \\
Microtainer without serum & $10 \mathrm{mM} \mathrm{HCl}$ & 3 & 0.27 \\
separator & & & \\
ditto, acid cleand & $10 \mathrm{mM} \mathrm{HCl}$ & 1.5 & $<0.02$ \\
Microtainer with serum & $10 \mathrm{mM} \mathrm{HCl}$ & 1.5 & 0.05 \\
separator, acid cleaned & & & \\
\hline
\end{tabular}

a. Plasma before storage, $1.21 \pm 0.05 \mathrm{ng} \mathrm{Mn} / \mathrm{ml}(n=6)$.

b. Yale $20 \mathrm{G}, 1.5$ inch in length.

The detection limit, i.e., the concentration giving the signal twice the noise deviation $(S / N=2)$, was 0.02 $\mathrm{ngMn} / \mathrm{ml}$ and the calibration curve was linear up to $5 \mathrm{ngMn} / \mathrm{ml}$ with $20 \mu \mathrm{l}$ injection. No detectable manganese was observed in $1 \mathrm{M}$ hydrochloric acid and $2 \%$ Triton X-100.

Amounts of manganese leached from various containers and syringes by water or $10 \mathrm{mM}$ hydrochloric acid are listed in Table 2. Vacutainers (BectonDickinson, No additive \#6526 and Sodium heparin \#6527) were widely used for sampling and storage of blood or serum, and accepted for trace element measurements partly due to the commercial availability. During 24-hour storage, significant amounts of manganese were leached out from these containers by water, $10 \mathrm{mM}$ hydrochloric acid and pooled plasma. Thus, these kind of tubes should not be recommended. Microtainer without serum separator, capillary blood collector (Becton-Dickinson, \#5962), could be allowed, if it is cleaned in the similar manner to that described above.

Disposable plastic syringes (Becton-Dickinson, 5 and $10 \mathrm{ml}, \# 5603$ and $\# 5604$ respectively) could also be allowed. In that case, it must be kept in mind that the major source of contamination would be stainless steel needles as shown in Table 2. The manganese samples from some needles (Becton-Dickinson, Yale 20G \#5176, Travenol Lab., Miniset 21G \#2C0073, Desert, Angiocath 22GA \#2962 and 18GA \#2955) were tested as follows. Into the disposable plastic syringe, $10 \mathrm{mM}$ hydrochloric acid was taken. After setting in place of a needle, each $1 \mathrm{ml}$ fraction was poured into five sample
Table 3 Manganese in serum taken successively

\begin{tabular}{|c|c|c|c|c|}
\hline \multirow{2}{*}{$\begin{array}{l}\text { Serum } \\
\text { fraction }\end{array}$} & \multicolumn{2}{|c|}{1 day storage } & \multicolumn{2}{|c|}{21 days storage } \\
\hline & $\begin{array}{c}\mathrm{Mn} / \\
\mathrm{ng} \mathrm{m}^{-1}\end{array}$ & $\begin{array}{c}\text { Visible } \\
\text { hemolysis }\end{array}$ & $\begin{array}{c}\mathrm{Mn} / \\
\mathrm{ng} \mathrm{ml^{-1 }}\end{array}$ & $\begin{array}{c}\text { Visible } \\
\text { hemolysis }\end{array}$ \\
\hline 1 & 0.56 & - & 0.49 & - \\
\hline 2 & 0.53 & - & 0.48 & - \\
\hline 3 & 0.52 & \pm & 0.52 & - \\
\hline 4 & $(0.73)$ & - & 0.51 & \pm \\
\hline 5 & 0.50 & - & 0.52 & $+t$ \\
\hline 6 & 0.52 & - & 0.55 & - \\
\hline 7 & 0.51 & \pm & 0.53 & \pm \\
\hline 8 & 0.50 & - & 0.54 & - \\
\hline 9 & 0.50 & + & 0.55 & - \\
\hline 10 & 0.52 & + & 0.50 & + \\
\hline Average $\pm S D$ & \multicolumn{2}{|c|}{$0.52 \pm 0.02$} & \multicolumn{2}{|c|}{$0.52 \pm 0.02$} \\
\hline R.S.D., \% & \multicolumn{2}{|c|}{3.8} & \multicolumn{2}{|c|}{3.8} \\
\hline
\end{tabular}

cups succesively through the needle, and manganese was measured immediately. The first fraction from the stainless steel needle (Yale) contained manganese in the range from 0.02 to $2.33 \mathrm{ng} / \mathrm{ml} \quad(n=9)$, whereas subsequent fractions contained manganese in less concentrations. The other needles showed no detectable contaminations.

The findings mentioned above positively recommended that we collect blood by auto-bleeding from the vein through an outer catheter into a polypropylene tube directly and that we store the serum in a small polypropylene tube after centrifugation in order to minimize contaminations. In cases where autobleeding was not possible, the use of a plastic syringe could be allowed.

\section{Analytical results}

The present methods were applied to two series of sera taken from one donor on different dates. Each $1.2 \mathrm{ml}$ of blood was sampled successively, and treated according to the recommended procedure. One series was analyzed on the day following the sampling and the other after 3 weeks. The results are shown in Table 3. Irrespective to the slightly visible hemolysis, all values agreed quite well with each other except for the value of $0.73 \mathrm{ngMn} / \mathrm{ml}$. This high value would be due to the spontaneous contamination from our laboratory environment. The analytical values obtained also agreed with those obtained for normal serum by neutron activation analysis. ${ }^{3,4}$ Such small relative standard deviations have not so far been reported. Provided there is no change in serum manganese of the donor between sampling intervals of 3 weeks, the storage for as long as 3 weeks could be allowed.

Present methods required only $200 \mu$ of serum and are very simple and reproducible, even though one sample analysis required ca. $20 \mathrm{~min}$. 
The authors thank Dr. Robert E. Lopez for giving us plasma and Dr. Y. Park for sampling of blood. One of us (T.U.) would like to thank Prof. C. Iida, Nagoya Institute of Technology, for his continuous encouragement throughout the work and for many suggestions about this manuscript.

\section{References}

1. J. Versieck and R. Cornelis, Anal. Chim. Acta, 116, 217 (1980).

2. E. Damsgaard, K. Heydorn, N. A. Larsen and B. Nielsen, RISO-Report No. 271 (1973); Chem. Abstr., 81, 47077t (1974).

3. J. Versieck, F. Barbier, A. Speecke and J. Hoste, Clin. Chem., 20, 1141 (1974).
4. G. C. Cotzias, S. T. Miller and J. Edwards, J. Lab. Clin. Med., 67, 836 (1966).

5. A. A. Fernandez, C. Sobel and S. L. Jacobs, Anal. Chem., 35, 1721 (1963).

6. D. J. D Amico and H. L. Klawans, Anal. Chem., 48, 1469 (1976).

7. J. Versieck, A. Speecke, J. Hoste and F. Barbier, Clin. Chem., 19, 472 (1973).

8. B. Grafflage, G. Buttgereit, W. Kubler and H. Mertens, Z. Klin. Chem. Klin. Biochem., 12, 287 (1974).

9. M. Zief and J. W. Mitchell, "Contamination Control in Trace Element Analysis", John Wiley \& Sons, New York (1976).

(Received October 3, 1985)

(Accepted November 14, 1985) 